\title{
Differences by Economic Status in Grade 3 Reading Performance: A Texas Multiyear Study
}

\author{
By Jenny A. M. McGown ${ }^{*}$ \& John R. Slate
}

In this investigation, differences in the reading performance as a function of degree of economic disadvantage for Texas Grade 3 students were examined. Data were obtained from the Texas Education Agency on all Texas Grade 3 students for the 2012-2013, 2013-2014, and 2014-2015 school years. In all analyses, statistically significant differences, with small to moderate effect sizes, were present in reading performance, as measured by the State of Texas Assessment of Academic Readiness, by student economic status. For all three Reading Reporting categories, a "stair-step of achievement effect" was present in that the greater the degree of poverty the lower student reading scores were. Analyses of passing standards revealed a similar pattern in that the greater the degree of poverty, the less likely students were to meet the passing standard. Suggestions for future research and implications for policy and practice were made.

Keywords: economically disadvantaged, literacy, reading skills, STAAR, Texas.

\section{Introduction}

With more children living in poverty in the United States today than during the Great Depression (Potter, 2015), the academic performance of these children and their ability for upward social mobility should be of upmost importance. As a nation, education historically has been hailed as the great equalizer, the vehicle of democracy driving the attainment of the American Dream. Yet repeatedly, researchers (e.g., Hagans \& Good, 2013; Reardon, 2013; Saez, 2012) have revealed an ever-widening gap in academic success between students in poverty and students who are not in poverty. This "income inequality gap" (Reardon, Valentino, \& Shores, 2012, p. 29) has now surpassed historical racial achievement gaps, increasing to the point that family income is now the best predictor of a child's academic success.

This reality appears in the results of standardized testing, particularly as it pertains to student literacy, a fundamental life skill needed for success (Reardon, 2013). As with grades, graduation rates, college admission, and degree completion, students from higher economic status groups outperform students from lower economic status groups on standardized assessments (Lee \& Slate, 2014). To provide a foundation for the reader, some of the research related to the disparities in student achievement of students in poverty, particularly as it pertains to literacy, is summarized briefly here.

\footnotetext{
*Deputy Superintendent, Klein Independent School District, USA.

'Professor, Sam Houston State University, USA.
} 


\section{Literacy and Reading Skills}

To begin, the complexity of the word literacy and what it means to be literate involves a broad spectrum of definitions. For purposes of this study, literacy is defined as "the ability to access, evaluate, and integrate information from a wide range of textual sources" (Reardon, Valentino, \& Shores, 2012, p. 18) and encompasses a complex set of skills (i.e., phonological, comprehension, analysis) that students acquire most rapidly during the elementary and middle school years (Reardon, Valentino, \& Shores, 2012). To meet minimum requirements on state assessments, student must demonstrate basic reading skills (Garcia \& Cain, 2014).

In Texas, reading skills are defined across the three reporting categories of the State of Texas Assessment of Academic Readiness (STAAR) Reading exam in Grade 3. Students' ability to demonstrate basic reading understanding across genres (i.e., fiction, poetry, drama, literary non-fiction, expository, persuasive) by determining "the meaning of grade-level academic words in English, using context to determine the meaning of unfamiliar words, and comparing and contrasting themes or moral lessons" is assessed in Reporting Category 1 (Texas Education Agency Student Assessment Division, 2011, para. 3). In Reporting Category 2, students must demonstrate the ability "to comprehend and analyze literary texts (i.e. fiction, poetry, drama, literary nonfiction) for elements such as foreshadowing, character development, sensory detail, and figurative language" (Texas Education Agency Student Assessment Division, 2011, para. 4). For Reporting Category 3, students must be able "to comprehend and analyze informational texts (i.e. expository, persuasive) by demonstrating the ability to summarize the main idea and supporting details, analyze organizational patterns and text features, and make logical connections between ideas and across texts" (Texas Education Agency Student Assessment Division, 2011, para. 5). As previously noted, the acquisition of these basic reading comprehension and analysis skills is foundational for individual success not only in school but also for future economic success (Stinnett, 2014). As such, questions remain regarding the degree of literacy students have and the extent to which disparities exist by economic status.

\section{Economic Disadvantage}

Inequities in the income achievement gap have grown increasingly over the last several decades. To determine the extent by which income-related achievement gaps increased or decreased over time, Reardon (2013) examined the relationship between family income and student achievement over the last 50 years in the United States. In his analysis of 12 nationally representative studies, the reading achievement gap by socioeconomic status began to grow in the mid-1970s and had widened approximately $40 \%$ since that time. Additionally, Reardon (2013) revealed that although the racial inequality gap has decreased over time, economic inequality has reached "historic highs" (2013, p. 12). 
Sadly, the economic achievement gap widens almost immediately from birth, as students from low-income families lack academic opportunities and rigor in the early years and are more likely to be raised in an information-poor environment with limited exposure to after-school and summer enrichment programs (Burney \& Beilke, 2008). The result is not only large achievement gaps evident when students enter Kindergarten, but achievement gaps that widen incrementally over time. Subsequently, Reardon (2013) purported that narrowing the inequality gap must be a joint effort between schools and policy makers, and that more financial and human capital should be expended for early intervention during the primary school years.

Along these lines, Hagans and Good (2013) conducted a study to determine the influence of early literacy intervention on reading skills of students from affluent and poor economic backgrounds. In their examination of 75 Grade 1 students from three different elementary schools, both economic status and student instructional group were examined in relation to oral reading fluency skills. Statistically significant differences were revealed between students who were at or below the poverty line and those students from middle or high economic backgrounds. Students from a low economic background were determined to be at a disproportionately increased risk for reading problems even after targeted instructional intervention (Hagans \& Good, 2013).

Similarly, Reardon, Valentino, \& Shores (2012) revealed an increase in the performance gap as a function of economic status when examining how well students in the United States read. In an analysis of data from national and international literacy assessments, literacy skills varied tremendously among student groups by race, ethnicity, and socioeconomic status. Although gaps in racial and ethnic disparities decreased over the last 40 years, Reardon, Valentino, \& Shores, (2012) discovered an increase in the performance gap for students in poverty. Black and Hispanic students entered high school three years further behind in reading than White and Asian students, yet students who were economically disadvantaged had literacy skills more than five years behind students from affluent backgrounds (Reardon, Valentino, \& Shores, 2012).

Eamon (2002) analyzed data on 1,324 students between the ages of 12 and 14 in New York. An analysis of the mother/child National Longitudinal Survey of Youth (2009) was utilized to determine not only the connections between poverty and lower achievement in reading and math but also the influence of mitigating variables (e.g., stimulating home environments) affecting student success (Eamon, 2002). Consistent with other researchers (e.g., Eamon, 2002; Kornrich \& Furtsenberg, 2013), students living in poverty underperformed students who were not economically disadvantaged regardless of ethnicity or race. Moreover, reading achievement correlated specifically to the cognitive home environment and the parent-to-child ratio, whereas poverty connected directly to school behavior problems (Eamon, 2002).

In a recent study in the state of interest for this investigation, Lee and Slate (2014) conducted a quantitative study of high school students in Texas to determine the extent to which differences might be present in advanced achievement in reading and math as a function of economic disadvantage. In 
their analysis of the exit-level results of the Texas Assessment of Knowledge and Skills for over 150,000 students, almost $43 \%$ of the sample was students living in poverty (Lee \& Slate, 2014). For the Commended Performance and the college-readiness indicator, statistically significant difference existed in both subjects. Students who were economically disadvantaged were considerably less likely to meet an advanced performance standard on the state-mandated assessments than were students who were not economically disadvantaged (Lee \& Slate, 2014). The implications of this disparity in performance included potentially limited access to college admissions and the subsequent effect not only on the individuals involved but also on the economy (Lee \& Slate, 2014). Recommendations for further research included an analysis of the differences that exist in advanced academic performance at other grade levels and other subject areas, as well as the relationship between teacher expectations and advanced performance of students (Lee \& Slate, 2014; Wright, Slate, \& Moore, 2016).

\section{Statement of the Problem}

As indicated in the review of the literature, a tremendous disparity exists between the performance of students in poverty and students with more affluent circumstances. This gap in performance stems at least in part from a lack of educational resources and exposure during a child's early development prior to entering school. For example, in 2005, parents in the highest income quintile spent nearly seven times more on their child's educational enrichment and development during the formative years than did their counterparts in the lowest income quintile (Kornrich \& Furtsenberg, 2013). Although educators have little control over a child's initial environment, the purpose of the No Child Left Behind Act (2002) was to ensure that all students, regardless of economic status, met at least a basic proficiency level of academic readiness as a result of their education (Lee \& Slate, 2014).

In Texas, this level of academic proficiency is measured by the State of Texas Assessment of Academic Readiness (STAAR) test, administered annually in reading beginning in Grade 3. Since the inception of the STAAR test in 2012, simply meeting the standard or basic level of academic proficiency has remained challenging for students, especially those students in poverty. Moreover, although in this latest accountability system the state consistently measures and monitors the performance of historically low-performing groups, little progress has been made in actually closing the income inequality gaps plaguing most schools in Texas, and across the nation for that matter, particularly with regard to literacy (Reardon, Valentino, \& Shores, 2012; Wright, Slate, \& Moore, 2016). In fact, despite large investments of financial and human capital, economic inequality has reached a historic high, exceeding racial inequalities in education outcomes (Saez, 2012). Furthermore, children from low economic backgrounds are at an increased risk of reading problems (Hagans \& Good, 2013). For example, although revealed in a report from the National Assessment 
of Educational Progress were modest improvements in the overall proficiency of all students in reading from 2009 to 2013, merely 17\% of 4th graders who were economically disadvantaged scored at or above proficient in reading (Stinnett, 2014). As children move through the education system, unfortunately things appear even bleaker, as students from low-income families enter high school with average literacy skills five years behind the literacy skills of highincome students (Stinnett, 2014). Not only should these outcomes alarm educators from the standpoint of equality and social justice, these disparities should concern all citizens in a democratic society and global economy. A concerted effort is necessary to ensure all students learn at high levels and to close quickly this ever-widening gap; the American Dream-through hard work and education even people of modest means can mobilize above their initial economic class - may remain just that, a dream.

\section{Purpose of the Study}

Given the moral imperative to ensure equality in all realms of society and the importance placed on high levels of learning for all students, including those students who are economically disadvantaged, as stated by the No Child Left Behind Act (2002) and measured by the State of Texas annually, an examination of the current economic achievement gap with regard to literacy is paramount. The purpose of this study was to determine the extent to which differences are present for Texas elementary school students in Grade 3 in their STAAR Reading performance as a function of degree of economic disadvantage. Results from Grade 5 were not analyzed because students in this grade level are required to participate in the Texas Student Success Initiative, and therefore do not receive multiple opportunities to demonstrate mastery of the assessed skills (Texas Education Agency, 2016b). By analyzing the differences in performance among students who are extremely poor, moderately poor, and not poor during the formative years of STAAR testing, educators may be able to determine an effective response for early intervention in closing the economic achievement gap.

\section{Significance of the Study}

Clearly, a large body of research (e.g., Eamon, 2002; Kornrich \& Furtsenberg, 2013; Lee \& Slate, 2014; Saez, 2012) has already been conducted regarding the presence of direct connections between academic achievement and economic status. Many empirical investigations are available concerning disparities in literacy rates nationally and internationally as a function of poverty. Few researchers, however, have focused their efforts on the relationship between poverty and literacy in the formative elementary school years as measured by the recently developed State of Texas Assessment of Academic Readiness. Furthermore, an analysis of the relationship between degrees of economic 
disadvantage and reading performance has not been examined to date. By analyzing the differences in the performance of students who qualified for reduced lunch (e.g., moderately poor) and those students who qualified for free lunch (e.g., extremely poor), the gradation of student poverty and its relationship to reading skills acquisition can be revealed. The findings of this study may have practical applications for educational leaders such as principals, literacy coaches, and classroom teachers-particularly at the elementary level in Texas-in ensuring all students become literate regardless of degrees of economic disadvantage. By determining the relationship between the depth of student poverty and the likelihood of the student achieving the basic reading proficiency, educators could direct quality early interventions to students in a timely and effective manner. As a result of these findings, state and district level policymakers could develop a comprehensive strategy to close the economic achievement gap.

\section{Research Questions}

The following overarching research question was addressed in this empirical investigation: What is the difference in the reading performance of Texas elementary school students in Grade 3 as a function of degree of economic status (i.e., Not Economically Disadvantaged, Moderately Poor, and Extremely Poor) for the 2012-2013 school year? Specific sub questions under this overarching research question were: (a) What is the difference in understanding across genres of Texas elementary school students in Grade 3 as a function of degree of economic status for the 2012-2013 school year?; (b) What is the difference in comprehension and analysis of literary texts of Texas elementary school students in Grade 3 as a function of degree of economic status for the 2012-2013 school year?; (c) What is the difference in comprehension and analysis of informative texts of Texas elementary school students in Grade 3 as a function of degree of economic status for the 2012-2013 school year?; (d) What is the effect of economic status on the Level II Final Satisfactory reading performance for Grade 3 students?; and (e) What is the extent to which a trend is present in reading skills of Texas elementary school students in Grade 3 as a function of degree of economic status for the 2012-2013 through the 20142015 school years? The first four research questions were repeated for the 2012-2013, 2013-2014, and 2014-2015 school years, whereas the fifth research question was repeated for the three reading objectives. Thus, 37 research questions comprised this investigation.

\section{Method}

\section{Research Design}

For this article, the research design utilized was an explanatory longitudinal 
investigation (Johnson, 2001). Archival data were used in examining past assessment results. The individual variables had already occurred and extraneous variables were not controlled in this study design (Johnson \& Christensen, 2012). Accordingly, the independent variable in this research article was the degree of economic disadvantage and the three dependent variables were the STAAR Reading Grade 3 scores in the three reading objectives and the Level II Final Satisfactory Performance Standard for the 2012-2013 through the 2014-2015 school years.

\section{Participants}

Archival data were obtained for the 2012-2013 through the 2014-2015 school years from the Texas Education Agency Public Education Information Management System for all students who took the STAAR Reading assessments in Grade 3. Although the STAAR Reading exam is also administered in Grades 4 and 5, the STAAR Reading exam in Grade 3 is the first opportunity to gauge mastery of student reading skills in a standardized summative assessment. A Public Information Request form was submitted previously to obtain these data for an Advanced Statistics course.

For the purpose of this article, the degree of economic disadvantage was defined based on the eligibility criteria outlined by the Texas Education Agency. Eligibility for free meals necessitates family income of $130 \%$ or less of the federal poverty line, whereas eligibility for reduced-price meals requires family income of $131 \%$ to $185 \%$ of the federal poverty line (Burney \& Beilke, 2008). This delineation of economic status was defined as follows: Extremely Poor (i.e., those students who qualify for the federal free-lunch program), Moderately Poor (i.e., those students who qualify for federal reduced-lunch program), and Not Economically Disadvantaged (i.e., those students who did not qualify for the federal free- nor reduced-lunch program).

\section{Instrumentation}

Scores from the STAAR Reading assessment for students in Grade 3 were analyzed. The STAAR Reading test measures student mastery of three reporting categories. Reporting Category 1 is a measure of a student's ability to understand and analyze a variety of texts across reading genres and contains six multiple choice items (Texas Education Agency Student Assessment Division, 2011, p. 2). Reporting Category 2 is a measure of a student's ability to understand and analyze literary texts and contains 18 multiple choice items (Texas Education Agency Student Assessment Division, 2011, p. 3). Reporting Category 3 is a measure of a student's ability to understand and analyze informational texts and contains 16 multiple choice items (Texas Education Agency Student Assessment Division, 2011, p. 4). In the previously discussed research questions, Reporting Category 1 constituted the dependent variable in the first research question, Reporting Category 2 constitutes the dependent variable in the second research question, and Reporting Category 3 is the dependent variable in the 
third research question.

Within each reporting category are Readiness Standards and Supporting Standards that assess grade level content as defined by the Texas Essential Knowledge and Skills (TEKS). Readiness Standards vary for each grade level but are characterized by being "essential for success" in the current grade level and "important for preparedness" for the next grade level by addressing significant content and concepts (Texas Education Agency STAAR Performance Standards, 2013, p. 26). Supporting Standards are those "more narrowly defined" content and concepts that are introduced in the current grade level and prepare students for the next grade level but are not critical to master in the current grade level (Texas Education Agency STAAR Performance Standards, 2013, p. 26). Additionally, students are expected to demonstrate "a flexible range of metacognitive reading skills in both assigned and independent reading to understand an author's message... as they become self-directed, critical readers" by being assessed in their mastery of Figure 19, a TEKS process standard, across the three Reporting Categories (Texas Education Agency Student Assessment Division, 2011, p. 4). Readers are directed to the Texas Education Agency website for information regarding the score validity and score reliability of the STAAR Reading assessment.

\section{Results}

Prior to conducting any inferential statistical procedures, the underlying assumptions of the multivariate analysis of variance (MANOVA) procedure were checked. Specifically examined were data normality, Box's Test of Equality of Covariance and the Levene's Test of Equality of Error Variances. Although the majority of these assumptions were not met, the robustness of a MANOVA procedure made it appropriate to use on the data in this study (Field, 2009).

Results of statistical analyses for students who were Extremely Poor, Moderately Poor, and Not Poor will be described by Reading Reporting Category. As mentioned previously, the STAAR Reading Reporting Categories are as follows: (a) Reporting Category 1: understanding and analysis across genres; (b) Reporting Category 2: understanding and analysis of literary texts; and (c) Reporting Category 3: understanding and analysis of informational texts. Results will be presented in chronological order beginning with the 2012-2013 school year and concluding with the 2014-2015 school year.

\section{Overall Results for the Three School Years}

With respect to the 2012-2013 school year, the MANOVA revealed a statistically significant overall difference, Wilks' $\Lambda=.88, p<.001$, partial $\eta^{2}=$ .06 , in reading performance as a function of economic status. Using Cohen's (1988) criteria, the effect size was moderate. Concerning the 2013-2014 school year, the MANOVA revealed a statistically significant difference, Wilks' $\Lambda=$ 
$.88, p<.001$, partial $\eta^{2}=.06$, in overall reading performance as a function of economic status. Using Cohen's (1988) criteria, the effect size was moderate. Regarding the 2014-2015 school year, the MANOVA revealed a statistically significant difference, Wilks' $\Lambda=.90, p<.001$, partial $\eta^{2}=.05$, in overall reading performance as a function of economic status. Using Cohen's (1988) criteria, the effect size was moderate. Statistically significant differences were revealed in all three school years in the overall reading skills for the three groups of students (i.e., Extremely Poor, Moderately Poor, and Not Economically Disadvantaged). The effect sizes for all three school years were reflective of a moderate degree of practical meaningfulness.

\section{Results for Reading Reporting Category 1: Understanding and Analysis across Genres}

For each of the three school years, univariate follow-up analysis of variance (ANOVA) procedures yielded statistically significant differences in student performance on the STAAR Reading Reporting Category 1. For the 2012-2013 school year, a statistically significant difference was revealed, $F(1,42039)=$ $17987.20, p<.001$, partial $\eta^{2}=.10$, moderate effect size. For the 2013-2014 school year, a statistically significant difference was yielded, $F(1,41523)=$ $17968.29, p<.001$, partial $\eta^{2}=.09$, moderate effect size. Finally, for the 20142015 school year, a statistically significant difference was revealed, $F(1$, $32690)=13151.00, p<.001$, partial $\eta^{2}=.07$, moderate effect size. Effect sizes were moderate for all three school years on the STAAR Reading Reporting Category 1.

To determine which pairs of student groups differed from each other in their Reading Reporting Category performance, Scheffe' post hoc procedures were conducted. These post hoc procedures revealed that statistically significant differences were present by degree of economic disadvantage for all three school years for Reporting Category 1 . Of the six questions on the assessment contained in this reporting category, a stair-step effect (Carpenter, Ramirez, \& Severn, 2006) was present for Reporting Category 1 in that the greater the degree of poverty the lower the Reading Reporting Category 1 score was. That is, students who were Extremely Poor scored statistically significantly lower on the Reading Reporting Category 1 than did students who were Moderately Poor, and students who were Moderately Poor scored statistically significantly lower than did students who were Not Poor. Readers are referred to Table 1 for the descriptive statistics for students' Reading Reporting Category 1 scores by their degree of economic status for each of the three school years. 
Table 1. Descriptive Statistics for the STAAR Grade 3 Reporting Category 1 Scores by Economic Status for the 2012-2013, 2013-2014, and 2014-2015 School Years

\begin{tabular}{|l|c|c|c|}
\hline School Year and Economic Status & $\mathbf{n}$ & M & SD \\
\hline $2012-2013$ & & & \\
\hline Not Poor & 138,884 & 4.73 & 1.40 \\
\hline Moderately Poor & 24,729 & 4.14 & 1.55 \\
\hline Extremely Poor & 177,686 & 3.70 & 1.62 \\
\hline $2013-2014$ & & & \\
\hline Not Poor & 140,570 & 4.85 & 1.36 \\
\hline Moderately Poor & 25,772 & 4.27 & 1.54 \\
\hline Extremely Poor & 180,170 & 3.83 & 1.63 \\
\hline $2014-2015$ & & & \\
\hline Not Poor & 148,996 & 4.51 & 1.49 \\
\hline Moderately Poor & 24,785 & 4.00 & 1.58 \\
\hline Extremely Poor & 184,369 & 3.62 & 1.64 \\
\hline
\end{tabular}

\section{Results for Reading Reporting Category 2: Understanding and Analysis of Literary Texts}

For each of the three school years, univariate follow-up ANOVA procedures yielded statistically significant differences in student performance on STAAR Reading Reporting Category 2. Statistically significant differences were revealed for the 2012-2013 school year, $F(1,207639)=14136.76, p<.001$, partial $\eta^{2}=$ .09 , moderate effect size; for the 2013-2014 school year, $F(1,257563)=$ 19868.95, $p<.001$, partial $\eta^{2}=.10$, moderate effect size; and for the 2014-2015 school year, $F(1,253314)=16910.17, p<.001$, partial $\eta^{2}=.09$, moderate effect size. Effect sizes were moderate for all three school years on the STAAR Reading Reporting Category 2.

Scheffe' post hoc procedures revealed that statistically significant differences were present by degree of economic disadvantage for all three school years for Reading Reporting Category 2. Of the 18 questions on the assessment contained in this reporting category, a stair-step effect (Carpenter, Ramirez, \& Severn, 2006) was present for Reading Reporting Category 2 in that the greater the degree of economic disadvantage the lower students' reading scores were. That is, students who were Extremely Poor scored statistically significantly lower on the Reading Reporting Category 2 than students who were Moderately Poor, and students who were Moderately Poor scored statistically significantly lower than students who were Not Poor. Delineated in Table 2 are the descriptive statistics for students' STAAR Reading Reporting Category 2 scores by degree of economic disadvantage for each of the three school years. 
Table 2. Descriptive Statistics for the STAAR Grade 3 Reporting Category 2 Scores by Economic Status for the 2012-2013, 2013-2014, and 2014-2015 School Years

\begin{tabular}{|l|c|c|c|}
\hline School Year and Economic Status & $\boldsymbol{n}$ & $\boldsymbol{M}$ & $\boldsymbol{S D}$ \\
\hline $2012-2013$ & & & \\
\hline Not Poor & 138,884 & 12.71 & 3.37 \\
\hline Moderately Poor & 24,729 & 11.39 & 3.59 \\
\hline Extremely Poor & 177,686 & 10.41 & 3.75 \\
\hline $2013-2014$ & & & \\
\hline Not Poor & 140,570 & 13.40 & 3.34 \\
\hline Moderately Poor & 25,772 & 11.95 & 3.61 \\
\hline Extremely Poor & 180,170 & 11.96 & 3.79 \\
\hline $2014-2015$ & & & \\
\hline Not Poor & 148,996 & 12.55 & 3.77 \\
\hline Moderately Poor & 24,785 & 11.14 & 3.86 \\
\hline Extremely Poor & 184,369 & 10.07 & 3.95 \\
\hline
\end{tabular}

\section{Results for Reading Reporting Category 3: Understanding and Analysis of Informational Texts}

With respect to each of the three school years, univariate follow-up ANOVA procedures yielded statistically significant differences in student performance on the STAAR Reading Reporting Category 3. Statistically significant differences were revealed for the 2012-2013 school year, $F(1,194237)=18666.01, p<$ .001 , partial $\eta^{2}=.10$, moderate effect size; for the 2013-2014 school year, $F(1$, $257563)=19868.95, p<.001$, partial $\eta^{2}=.10$, moderate effect size; and for the 2014-2015 school year, $F(1,253314)=16910.17, p<.001$, partial $\eta^{2}=.09$, moderate effect size. Effect sizes were moderate for all three school years on the STAAR Reading Reporting Category 3.

Scheffe' post hoc procedures revealed that statistically significant differences were present by degree of economic disadvantage for all three school years for Reporting Category 3. Of the 16 questions on the assessment contained in Reporting Category 3, as evident in the previous reporting category results, a stair-step effect (Carpenter, Ramirez, \& Severn, 2006) was present for Reporting Category 3 in that the greater the degree of economic disadvantages the lower students' scores were evident. That is, students who were Extremely Poor scored statistically significantly lower on Reporting Category 3 than students who were Moderately Poor, and students who were Moderately Poor scored statistically significantly lower than students who were Not Poor. Readers are referred to Table 3 for the descriptive statistics for students' STAAR Grade 3 Reading scores for Reporting Category3 and degree of economic status for each of the three school years. 
Table 3. Descriptive Statistics for the STAAR Grade 3 Reporting Category 3 Scores by Economic Status for the 2012-2013, 2013-2014, and 2014-2015 School Years

\begin{tabular}{|l|c|c|c|}
\hline School Year and Economic Status & $\mathbf{n}$ & M & SD \\
\hline $2012-2013$ & & & \\
\hline Not Poor & 177,686 & 11.63 & 3.07 \\
\hline Moderately Poor & 24,729 & 10.33 & 3.23 \\
\hline Extremely Poor & 177,686 & 9.40 & 3.34 \\
\hline $2013-2014$ & & & \\
\hline Not Poor & 140,570 & 11.21 & 3.25 \\
\hline Moderately Poor & 25,772 & 9.86 & 3.36 \\
\hline Extremely Poor & 180,170 & 8.88 & 3.43 \\
\hline $2014-2015$ & & & \\
\hline Not Poor & 148,996 & 11.70 & 3.26 \\
\hline Moderately Poor & 24,785 & 10.46 & 3.35 \\
\hline Extremely Poor & 184,369 & 9.48 & 3.46 \\
\hline
\end{tabular}

\section{Overall Results for the Level II Final Satisfactory Performance Standard}

Because the raw scores for each Reading Reporting Category were statistically significantly different by student economic status, a decision was made to analyze the percentage of students who met the Level II Final Satisfactory Performance Standard to gauge progress in closing achievement gaps. That is, differences in raw scores may or may not translate to differences in students meeting the performance standard in reading. Public schools in Texas are held accountable not for student raw score performance but rather on the extent to which their students meet the performance standard.

To determine whether a difference was present in the Level II Final Satisfactory Performance Standard as measured by the Grade 3 STAAR Reading test by degree of economic disadvantage, Pearson chi-square procedures were calculated. This statistical procedure was viewed as the optimal statistical procedure to use because frequency data were present for the Level II Final Satisfactory Performance Standard and for economic status. As such, chisquares are the preferred statistical procedure when both variables are categorical (Field, 2013). In addition, with the large sample size, the available sample size per cell was more than five. Therefore, the assumptions for utilizing a chi-square were met.

Concerning the Level II Final Satisfactory Performance Standard by student economic status, the results for all three school years were statistically significant. For the 2012-2013 school year, the result, $\chi^{2}(2)=27384.79, p<$ .001 , yielded an effect size, Cramer's V, that was small, .28 (Cohen, 1988). For the 2013-2014 school year, the result was also statistically significant, $\chi^{2}(2)=$ $31177.91, p<.001$. The effect size for this finding, Cramer's V, was moderate, .30 (Cohen, 1988). Similarly, for the 2014-2015 school year, the result was also statistically significant, $\chi^{2}(2)=29642.40, p<.001$. The effect size for this finding, Cramer's V, was moderate, .30 (Cohen, 1988). Effect sizes for these analyses were small for one school year and moderate for two school years. 
As revealed in Table 4, for all three school years, a stair-step effect (Carpenter, Ramirez, \& Severn, 2006) was present. Higher percentages of students who were Not Poor met this Level II Final Satisfactory Performance Standard in all three school years than did students who were Moderately Poor and students who were Extremely Poor. The difference in percentages between the Not Poor and the Moderately Poor groups of students not meeting the standard was $18.9 \%, 19.4 \%$, and $18.9 \%$ for the three school years, respectively. Students who were Not Poor achieved the standard more frequently than those students who were Moderately Poor, and students who were Moderately Poor outperformed students who were Extremely Poor. Moreover, the largest gap in meeting the performance standard occurred between students who were Not Poor and students who were Extremely Poor with a difference in percentage of students not meeting the passing standard occurring $28.8 \%, 30.9 \%$, and $29.3 \%$ for the three school years, respectively. Similarly, students who were Not Poor were by far the most likely to meet the Level II Final Satisfactory Performance Standard in the 2012-2013, 2013-2014, and 2014-2015 school years than were students who were Moderately Poor or Extremely Poor. Table 4contains the descriptive statistics for these analyses.

Table 4. Frequencies and Percentages for the Grade 3 STAAR Reading Level II Satisfactory Performance Standard by Degree of Economic Disadvantage for the 2012-2013, 2013-2014, and 2014-2015 School Years

\begin{tabular}{|l|c|c|c|c|}
\hline & \multicolumn{2}{|c|}{ Met Standard } & \multicolumn{2}{c|}{ Did Not Meet Standard } \\
\hline $\begin{array}{l}\text { School Year and Economic } \\
\text { Status }\end{array}$ & $n$ & $\%$ & $n$ & $\%$ \\
\hline $2012-2013$ & & & & \\
\hline Not Poor & 79,205 & 56.5 & 60,884 & 43.5 \\
\hline Moderately Poor & 9,394 & 37.6 & 15,567 & 62.4 \\
\hline Extremely Poor & 49,781 & 27.7 & 130,106 & 72.3 \\
\hline $2013-2014$ & & & & \\
\hline Not Poor & 85,048 & 60.0 & 56,759 & 40.0 \\
\hline Moderately Poor & 10,579 & 40.6 & 15,451 & 59.4 \\
\hline Extremely Poor & 53,066 & 29.1 & 129,328 & 70.9 \\
\hline $2014-2015$ & & & & \\
\hline Not Poor & 80,959 & 54.8 & 66,656 & 45.2 \\
\hline Moderately Poor & 8,944 & 36.4 & 15,595 & 63.6 \\
\hline Extremely Poor & 46,348 & 25.5 & 135,331 & 74.5 \\
\hline
\end{tabular}

\section{Discussion}

The extent to which differences were present in the reading performance of Texas elementary school students by their economic status was examined in this investigation. Three years of statewide data on the three Grade 3 STAAR Reading Reporting Categories were analyzed for three different student groups: Not Poor, Moderately Poor, and Extremely Poor. In all three school years, statistically significant results were present. Following these statistical analyses, 
the presence of trends for the three reading performance reporting categories by degree of student economic status was determined. Results will be summarized in the next section.

\section{Reading Reporting Category 1: Understanding and Analysis across Genres}

Reading Reporting Category 1 contained six questions on the Grade 3 STAAR Reading assessment during each of the 2012-2013 through 2014-2015 school years. Students who were Not Poor scored 0.51 to 0.59 points higher on the Reading Reporting Category 1 than students who were Moderately Poor during the 2012-2013 through the 2014-2015 school years. Students who were Moderately Poor had an average score that was 0.38 to 0.44 points higher on the Reading Reporting Category 1 than students who were Extremely Poor.

To determine the magnitude of the difference between the average scores for the two groups of students in poverty (i.e., Moderately Poor and Extremely Poor) for each school year, a Cohen's $d$ was calculated between the Not Poor group and the Moderately Poor group and between the Not Poor group and the Extremely Poor group for Reading Reporting Category 1. The array of the Cohen's $d$ calculations ranged from a low of 0.33 (moderate effect size) to a high of 0.68 (moderate effect size). The average Cohen's $d$ was 0.51 (moderate effect size) for the three school years of data analyzed. Readers are referred to Table 5 for the Cohen's $d$ effect size calculations.

Table 5. Cohen's ds for Economic Status Differences in STAAR Grade 3 Results by Reporting Category for the 2012-2013 through the 2014-2015 School Years

\begin{tabular}{|l|c|c|c|}
\hline $\begin{array}{l}\text { School Year and } \\
\text { Economic Status }\end{array}$ & $\begin{array}{c}\text { Reporting } \\
\text { Category 1 } \boldsymbol{d}\end{array}$ & $\begin{array}{c}\text { Reporting } \\
\text { Category 2 } \boldsymbol{d}\end{array}$ & $\begin{array}{c}\text { Reporting } \\
\text { Category 3 } \boldsymbol{d}\end{array}$ \\
\hline $2012-2013$ & & & \\
\hline Moderately Poor & 0.40 & 0.38 & 0.41 \\
\hline Extremely Poor & 0.68 & 0.64 & 0.69 \\
\hline $2013-2014$ & & & 0.41 \\
\hline Moderately Poor & 0.40 & 0.42 & 0.70 \\
\hline Extremely Poor & 0.68 & 0.72 & 0.38 \\
\hline $2014-2015$ & & & 0.66 \\
\hline Moderately Poor & 0.33 & 0.37 & \\
\hline Extremely Poor & 0.57 & 0.64 & \\
\hline
\end{tabular}

\section{Reading Reporting Category 2: Understanding and Analysis of Literary Texts}

Reading Reporting Category 2 contained 18 questions on the STAAR Grade 3 Reading assessment during each of the 2012-2013 through 2014-2015 school years. Students who were Not Poor scored higher on Reading Reporting Category 2 than students who were Moderately Poor during the 2012-2013 through the 2014-2015 school years. Students who were Moderately Poor scored higher on Reporting Category 2 than students who were Extremely Poor. To determine the magnitude of the difference between the average scores for these 
three groups of students for each school year, a Cohen's $d$ was calculated for each school year for Reading Reporting Category 2. The array of the Cohen's $d$ calculations ranged from a low of 0.37 (small effect size) to a high of 0.72 (moderate effect size). The average effect size was 0.53 (moderate effect size) for the three years of data analyzed. Readers are referred to Table 5 for the Cohen's $d$ effect size calculations for the STAAR Reading Reporting Category 2.

\section{Reading Reporting Category 3: Comprehension and Analysis of Informational Texts}

Reading Reporting Category 3 contained 16 questions on the STAAR Grade 3 Reading assessment during each of the 2012-2013 through 2014-2015 school years. Students who were Not Poor scored higher on Reading Reporting Category 3 than students who were Moderately Poor during the 2012-2013 through the 2014-2015 school years. Students who were Moderately Poor scored higher on Reporting Category 3 than students who were Extremely Poor. To determine the magnitude of the difference between the average score for these three groups of students for each school year, a Cohen's $d$ was calculated for each school year for Reading Reporting Category 3. The array of the Cohen's $d$ calculations ranged from a low of 0.38 (small effect size) to a high of 0.70 (moderate effect size). The average effect size was 0.54 (moderate effect size) for the three years of data analyzed. Readers are referred to Table 5 for the Cohen's $d$ effect size calculations for the STAAR Reading Reporting Category 3.

\section{Overall Results for the Level II Final Satisfactory Performance Standard}

Consistent with other research studies (e.g., Reardon, 2013; Stinnett, 2014; Wright \& Slate, 2015) regarding the economic achievement gap, Texas students living in poverty or near-poverty conditions did not perform as well as their peers. At the first opportunity for student performance to be measured by the State of Texas Assessment of Academic Readiness in reading in Grade 3, statistically significant performance gaps by economic status occurred. A stairstep effect (Carpenter, Ramirez, \& Severn, 2006) was present both across reporting categories and the passing standard in that the achievement gap in performance increased the greater the degree of poverty. Additionally, reading achievement was the poorest for students who were Extremely Poor for all three school years.

\section{Connection with Existing Literature}

When examining reading performance, poverty definitely matters (Reardon, Valentino, \& Shores, 2012); the greater the degree of student poverty, the lower students' scores were, both by reporting category raw score and the overall percentage of students meeting the Level II Final Satisfactory Performance Standard. This difference in performance can be attributed in part to the fact 
that students from low-income families lack academic opportunities and rigor in the early years and are more likely to be raised in an information-poor environment with limited exposure to after-school and summer enrichment programs (Burney \& Beilke, 2008). The implications of this disparity in performance include potentially limited access to college admissions and the subsequent effect not only on the individuals involved but also on the economy (Lee \& Slate, 2014). Results of this research investigation are consistent with the outcomes of other researchers (Eamon, 2002; Kornrich \& Furtsenberg, 2013; Lee \& Slate, 2014; Saez, 2012) who noted the presence of lower reading achievement scores among students who are economically disadvantaged when compared to students who are not economically disadvantaged.

\section{Implications for Policy and Practice}

Clearly, economic disadvantage has a negative influence on literacy and reading performance on standardized assessments, as demonstrated by this longitudinal investigation in which STAAR Reading scores were analyzed. Despite concerted efforts for decades at the local, state, and federal level to address and close this gap, the gap sadly persists. This disparity in performance indicates the need for further collaborative efforts on behalf of policymakers and educators to close the achievement gap.

Certainly efforts have been made to provide additional funding to schools with a total student enrollment of over $40 \%$ of students who meet the definition of poverty (U.S. Department of Education, 2014, para. 5). That is, over 6,000 of the nearly 8,400 campuses in Texas receive some federal funding to assist students who are identified as economically disadvantaged (Education Bug, 2015). Additionally, state compensatory funds are available to students who are identified as "at-risk" in order to provide additional supports such an increased instructional time and targeted intervention (Texas Education Agency, 2016). However, given the rigorous academic standards students in Texas public schools are held to in a funding system recently acknowledged by the state Supreme Court as "undeniably imperfect, with immense room for improvement" (Collier, 2016, para. 6), the funding system obviously needs further attention and modifications to improve learning outcomes for Texas students, especially those students living in poverty.

Furthermore, as students in poverty demonstrate poorer reading skills immediately upon matriculation, federally funded programs such as Head Start and full-day Pre-Kindergarten are essential to providing foundational early literacy skills and preventing the widening of the achievement gap (Kornrich \& Furtsenberg, 2013). Additionally, high poverty schools have a higher concentration of inexperienced teachers (Haycock \& Crawford, 2008), who may not be as skilled in teaching reading and thereby further contribute to literacy gap. Teachers of all experience levels could benefit from the support of a Literacy Coach on staff to provide additional modeling and support of research-based best practices (Matsumura, Garnier, Correnti, Junker, \& Bickel, 2010). School districts should also regularly provide quality professional 
development on literacy practices, as solid reading skills are foundational to success in all other academic subjects and life beyond graduation. Subsequently, educators and policymakers should work collaboratively to ensure additional resources and targeted interventions are allocated to students of poverty, and even more so to those students qualifying for free lunch, so that foundational skills are established during the elementary school years prior to moving on to secondary and higher education.

\section{Recommendations for Future Research}

Commensurate with other researchers (e.g., Lee \& Slate, 2014; Reardon, 2013; Reardon, Valentino, \& Shores, 2012), the disparity in performance of students who were economically disadvantaged, and particularly those students who were extremely poor, was revealed by the large sample size represented in this study of over 358,150 students. Revealed in a study of this scale once more is the inequality in overall reading performance and literacy as a result of the degree of economic status. These results further indicate the need for targeted intervention and remediation as soon as students enter school (Hagans \& Good, 2013). As evidenced in the results from this multiyear investigation, a gap in achievement was already present at the first opportunity for standardized assessment by the state in third grade. This gap in achievement is cause for concern because should it continue as students are promoted through the school system, students living in poverty, especially those students qualifying for free lunch, may ultimately be at higher risk for lower high school completion rates, inequitable access to college admissions, and inability to compete well for high-earning jobs against students from more affluent backgrounds (Lee \& Slate, 2014).

Due to the recent development and implementation of the State of Texas Assessment of Academic Readiness program and therefore the limited longitudinal data available for analysis, further research is recommended in the future to examine the uniformity of the performance gap over time as measured by this standardized assessment. Additionally, researchers should examine other grade level data at the elementary school level to determine whether or not the gap closes as students are promoted in the system, as well as extend the examination to students in high school who must meet the passing standard in order to graduate. The study of student performance in other states where statemandated assessments occur could also contribute meaningfully to this body of research. Other questions that could be explored in future research related to the performance of students in Texas include (a) What differences exist in student Level III Advanced Performance for STAAR Reading and other STAAR-tested subjects (e.g., writing and science) by degree of economic disadvantage?; (b) What differences exist in student performance in Reading in other grades (i.e., Grades 4 through 8 and high school End of Course exams)?; and (c) Which early interventions in schools effectively narrow the economic achievement gap between students in poverty and those with more affluent family incomes? Quantitative, qualitative research, and mixed methods studies 
need to be conducted to address these questions. Results from such investigations could provide meaningful data to inform the practice of educational leaders and policymakers.

\section{Conclusion}

The purpose of this research study was to determine the extent to which differences were present in the reading performance of Texas elementary school students as a function of their economic status. After obtaining and analyzing three school years of Texas statewide data, statistically significant differences were revealed in the reading achievement of students who were Not Poor, Moderately Poor, and Extremely Poor. In each school year between 2012-2013 and 2014-2015, the average STAAR Grade 3 reading scores revealed a stair-step effect (Carpenter Ramirez, \& Severn, 2006) in that students who were Not Poor performed better than students who were Moderately Poor, and those students who were Moderately Poor performed better than those students who were Extremely Poor. Consistent with previous researchers (e.g., Eamon, 2002; Kornrich \& Furtsenberg, 2013; Lee \& Slate, 2014; Saez, 2012), students who were not economically disadvantaged outperformed students who were economically disadvantaged when reading performance was measured on the Grade 3 STAAR Reading exam. These results are cause for concern, particularly given the large numbers of Grade 3 students in Texas who met the poverty guidelines.

\section{References}

Burney, V. H., \& Beilke, J. R. (2008). The constraints of poverty on high achievement. Journal for the Education of the Gifted, 31, 171-197.

Carpenter, D. M., Ramirez, A., \& Severn, L. (2006). Gap or gaps: Challenging the singular definition of the achievement gap. Education and Urban Society, 39, 113-127. doi:10.1177/0013124506291792

Cohen, J. (1988). Statistical power analysis for the behavioral sciences (2nd ed.). Hillsdale, NJ: Lawrence Erlbaum.

Collier, K. (2016, May 13). Texas Supreme Court upholds school funding system. The Texas Tribune. Retrieved from https://bit.ly/2uspMpl.

Eamon, M. K. (2002). Effect of poverty on mathematics and reading achievement of young adolescents. The Journal of Early Adolescence, 22, 49-74. doi:10.1177/ 0272431602022001003

Education Bug (2015). Texas Public School Statistics. Retrieved from https://bit.ly/ 2G9Bzu0.

Field, A. (2013). Discovering statistics using SPSS (4th ed.). Thousand Oaks, CA: Sage.

Garcia, J. R., \& Cain, K. (2014). Decoding and reading comprehension: A meta-analysis to identify which reader and assessment characteristics influence the strength of the relationship in English. Review of Educational Research, 84, 74-111.

Hagans, K. S., \& Good III, R. H. (2013). Decreasing reading differences in children from disadvantaged backgrounds: The effects of an early literacy intervention. 
Contemporary School Psychology, 17, 103-117.

Haycock, K., \& Crawford, C. (2008). Closing the teacher quality gap. Educational Leadership, 65, 14-19.

Johnson, B. (2001). Toward a new classification of nonexperimental quantitative research. Educational Researcher, 30, 3-13. doi:10.3102/0013189X030002003

Johnson, R. B., \& Christensen, L. B. (2012). Educational research: Quantitative, qualitative, and mixed approaches (4th ed.). Los Angeles, CA: Sage.

Kornrich, S., \& Furstenberg, F. (2013). Investing in children: Changes in parental spending on children, 1972-2007. Demography, 50, 1-23.

Lee, K. M., \& Slate, J. R. (2014). Differences in advanced achievement outcomes for Texas students as a function of economic disadvantage. Journal of Education Research, 8(3), 137-149.

Matsumura, L. C., Garnier, H. E., Correnti, R., Junker, B. \& Bickel, D. D. (2010). Investigating the effectiveness of a comprehensive literacy coaching program in schools with high teacher mobility. The Elementary School Journal, 111, 35-62.

No Child Left Behind Act of 2001, Pub. L. No. 107-110, § 1001, 115 Stat. 1425. (2002).

Potter, K. (2015, July 21). More U.S. children are living in poverty than during the Great Depression. The Huffington Post. Retrieved from https://bit.ly/1HPdS3u.

Reardon, S. F. (2013). The widening income achievement gap. Educational Leadership, 70(8), 10-16.

Reardon, S. F., Valentino, R. A., \& Shores, K. A. (2012). Patterns of literacy among U.S. students. Future of Children, 22(2), 17-37.

Saez, E. (2012). Striking it richer: The evolution of top incomes in the United States (updated with 2009 and 2010 estimates). Berkeley. CA: Department of Economics, University of California at Berkeley. Retrieved from https://bit.ly/2ukDb2r.

Stinnett, M. (2014). The influence of poverty on literacy achievement .Illinois Reading Council Journal, 42(3), 65-69.

Texas Education Agency. (2011). STAAR Information Booklet. Austin, TX: Student Assessment Division. Retrieved from https://bit.ly/2DWb215.

Texas Education Agency. (2013). STAAR Performance Standards. Retrieved from https://bit.ly/2G5Uqdr.

Texas Education Agency. (2016b). Student Success Initiative Manual. Texas Education Agency. Retrieved from https://bit.ly/2DVvJu0.

U.S. Department of Education. (2014). Programs: Title I, Part A. Retrieved from https://bit.ly/1Qx45me.

Wright, L. A., \& Slate, J. R. (2015). Differences in critical thinking skills for Texas middle school students as a function of economic disadvantage. Journal of Education Research, 9(4).

Wright, L. A., Slate, J. R., \& Moore, G. W. (2016). Reading skill differences by economic status for Texas high school students: A multiyear, statewide analysis. Journal of Education Policy, Planning \& Administration, 6(2), 1-17. Retrieved from https://bit.ly/2GrRfMp. 
